\title{
Abnormal Hematology Test Result
}

National Cancer Institute

\section{Source}

National Cancer Institute. Abnormal Hematology Test Result. NCI Thesaurus. Code C35877.

A laboratory test result that indicates the presence of abnormal peripheral blood and/or bone marrow values. 